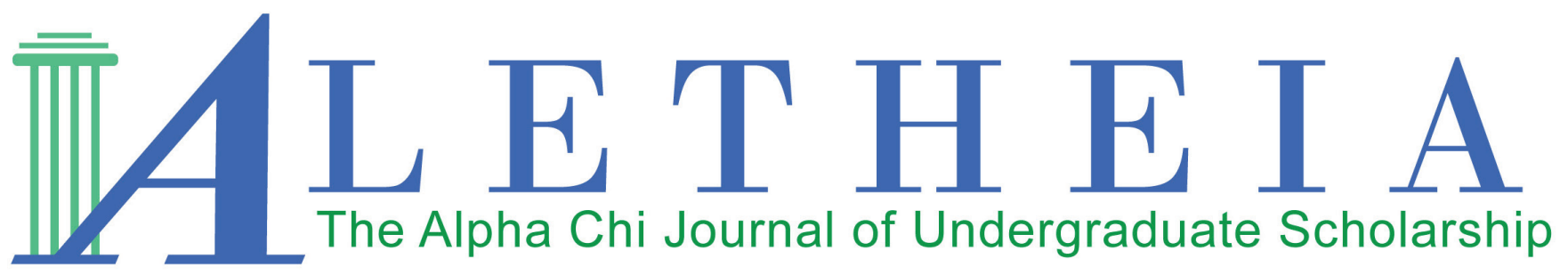

Volume 2 | Issue 1 | 2017

\title{
Examining the Consumer's Perspective of Patient Advocacy
}

\author{
Elizabeth Crawford \\ University of North Carolina Pembroke \\ North Carolina Kappa Chapter
}

Vol. 2(1), 2017

Article Title: Examining the Consumer's Perspective of Patient Advocacy

DOI: $10.21081 / \mathrm{AX} 0116$

ISSN: 2381-800X

Key Words: advocacy, nursing, patient advocacy, health consumer

This work is licensed under a Creative Commons Attribution 4.0 International License.

Author contact information is available from the Editor at editor@alphachihonor.org.

\section{Aletheia-The Alpha Chi Journal of Undergraduate Scholarship}

- This publication is an online, peer-reviewed, interdisciplinary undergraduate journal, whose mission is to promote high quality research and scholarship among undergraduates by showcasing exemplary work.

- Submissions can be in any basic or applied field of study, including the physical and life sciences, the social sciences, the humanities, education, engineering, and the arts.

- Publication in Aletheia will recognize students who excel academically and foster mentor/mentee relationships between faculty and students.

- In keeping with the strong tradition of student involvement in all levels of Alpha Chi, the journal will also provide a forum for students to become actively involved in the writing, peer review, and publication process.

- More information and instructions for authors is available under the publications tab at www.AlphaChiHonor.org. Questions to the editor may be directed to editor@alphachihonor.org.

\footnotetext{
Alpha Chi is a national college honor society that admits students from all academic disciplines, with membership limited to the top 10 percent of an institution's juniors, seniors, and graduate students. Invitation to membership comes only through an institutional chapter. A college seeking a chapter must grant baccalaureate degrees and be regionally accredited. Some 300 chapters, located in almost every state, induct approximately 12,000 members annually. Alpha Chi members have been "making scholarship effective for good" since 1922.
} 


\title{
Examining the Consumer's Perspective of Patient Advocacy
}

\author{
Elizabeth Crawford \\ University of North Carolina Pembroke \\ North Carolina Kappa Chapter
}

\begin{abstract}
Aim: The purpose of this study is to better define the concept of patient advocacy by examining the health consumer's perspective, creating a stronger basis for further research while better aiding the nursing student in self-reflection and refinement of individualized patient-centered care.

Background: A universally supported interpretation of patient advocacy has yet to be formulated, and previous research fails to examine the consumers' perception of the concept. To generate a more complete understanding of the constantly fluctuating concept of patient advocacy, consumer perspectives are explored. Method: Consisting of a total of eight students from a southeastern university, two focus groups were constructed to explore the healthcare consumer's perception of patient advocacy. Focus groups were audio recorded and then later transcribed and analyzed for prominent themes.

Findings: Five significant themes regarding the conceptualization of patient advocacy were identified, including healthcare professional personality characteristics; autonomy and self-determination; the patient's values, beliefs, rights, and desires; information disclosure; and patient safety.

Conclusion: The current study's findings further confirm the previous conceptualizations of patient advocacy. With the incorporation of the healthcare consumer's perceptions, healthcare professionals are more empowered to better serve their patients through a more complete understanding of how to refine advocacy practices in providing higher quality individualized patient-centered care.
\end{abstract}

Keywords: advocacy, nursing, patient advocacy, health consumer

\section{Introduction}

Advocacy is central to the scope and standards of practice for the nursing profession, as addressed in the American Nurses Association's (2015) contemporary definition of nursing. However, although the ANA has defined advocacy in their 2015 edition of the Scope and Standards of Practice, there is still a lack of agreement on the details and implication of the concept. Concept analyses, literature reviews, and empirical research have investigated the concept of advocacy with an aim to resolve discrepancies within its inconsistent interpreta- tion; however, the current research favors the healthcare professional's perspectives, failing to examine consumer-related philosophies. Without the consumer's view incorporated into the nurse's personal understanding and subsequent actions, individualized patient-centered nursing care becomes deficient. With a more thoroughly developed conceptualization of patient advocacy, one which integrates the consumers' thoughts and ideas, nurses will be better equipped to engage in self-reflection and refinement of individualized and advocacy-based patient-centered care, fostering promotive, supportive, and restorative nursing practices. In addition, with mul- 
tiple perspectives and different contexts, an increasingly comprehensive understanding of the constantly fluctuating concept of patient advocacy is generated, creating an improved basis for further research (Vaartio, Leino-Kilpi, Suominen, \& Puukka, 2008).

Because a universally supported interpretation of patient advocacy has yet to be formulated, and previous research fails to examine the consumers' perception of the concept, consumer perspectives should be explored in order to generate a more complete understanding of this constantly fluctuating concept. The purpose of this descriptive study is to construct a consumer-focused comprehensive interpretation of patient advocacy.

\section{Literature Review}

Hewitt (2002) argues against the nursing profession being the most suitable advocate for the patient. She suggests nursing professionals lack authority in comparison to physicians, concluding that in order to empower the patient though advocacy, the nurse must first be empowered. However, through the third provision in the ANA's Guide to the Code of Ethics for Nursing (2015a), nurses are empowered to practice advocacy and, furthermore, are "ethically bound to [promote and] protect the health, safety, and rights of the patient" (Schroeter, 2014, p. 87). Not only is the nurse in an appropriate position to advocate for the patient, but is also ethically bound to provide such care.

The ANA (2015b) has established the concept of advocacy to be a fundamental value of nursing practice, briefly and broadly conceptualizing it as "the act or process of pleading for, supporting, recommending a cause or course of action" (ANA, 2015b, p. 20). However, a universally supported and more extensive interpretation has yet to be formulated. Consistently observed themes of patient advocacy derived from varying research conclusions include topics such as (1) consumer autonomy and self-determination, (2) information disclosure, (3) consumer values, beliefs, and rights, (4) social justice, and (5) patient safety. Many of these topics build on each other and are expressed through varying levels of nursing responsibilities, ranging from simple to complex, and individualistic to social policy (ANA, 2015b; Schroeter, 2014). In 2015, the ANA published their third edition of Nursing: Scope and Standards of Practice, which includes a brief characterization of microsocial and macrosocial patient-advocacy-related nursing in- terventions; each level is broadly defined, leaving room for further research-based concept development. The review of the literature expands on the general conceptualizations of the ANA's scope and standards through consolidation of concept analyses, empirical research, editorials, and peer reviewed literature reviews.

The ANA's (2015b) first level of advocacy is that of the individual, requiring the nurse to engage in actions which provide the consumer with sufficient information, promoting the supplication of patient autonomy which is successfully upheld when a rational individual is able to make an informed and un-coerced decision. Schwartz (2002), along with Bu and Jezewski (2006), emphasize the importance of the preservation of patients' self-determination, drawing from nursing philosophies which focus on sufficient disclosure of information, encouragement of consumer value clarification, and promotion of fully informed decisions. When information is withheld with the goal of guiding the patient's and/or guardian's decision making, autonomy is compromised; the patient makes a decision based on insufficient information. The professional justifies his or her action, believing he or she knows what is best for the patient. In this case, the health professional's responsibility to "do good" for the benefit of the patient can lead to the elimination of the patient's self-determination, a human right which Gadow, a patient advocacy theorist, describes as fundamental (Bu \& Jezewski, 2006; Gadow, 1989). A fully cognitive individual may refuse medical treatment or oppose medical advice, in which the nurse, or other medical professional, may believe that to uphold the ethical responsibility of beneficence, the wishes and desires of the individual must be ignored to better serve their "best interest." However, according to Breier-Mackie (2001), when autonomy through self-determination is ignored, beneficence becomes integrated with paternalism, the intentional overriding of a "patient's preferences, decisions, or actions . . . out of concern for the patient's well-being" (as cited in Zomorodi \& Foley, 2009, p. 1747). To perpetuate patient advocacy through the preservation of patient autonomy, the nurse must (1) provide fully informative communication within the nurse-patient relationship, and (2) uphold the patient's values and beliefs through support of the patient's personal decision (Schwartz, 2002; Zomorodi \& Foley, 2009).

Patient empowerment through the provision of emotional support, informational support, and social support comprises the interpersonal nurse-patient rela- 
tionship, the second level of advocacy (ANA, 2015b). $\mathrm{Bu}$ and Jezewski (2006) expand on this aspect of advocacy, highlighting it as the representation and promotion of the patient's values, beliefs, and rights (Schwartz, 2002; Vaartio et al., 2008). As an advocate, the nurse is to aid the patient in value clarification, enabling decisions reached to be ones which reaffirm the consumer's personal beliefs and desires. Truly knowing what actions are in the best interest of the patient becomes possible only when the nurse is thoroughly knowledgeable about the patient's situation, background, thoughts and desires. To fully advocate for the consumer, "it is important for the nurse to really know the needs, desires, and wants of the individual ... when nurses 'rescue' individuals by guiding their decision-making, they are denying the individuals' autonomy" (Zomorodi \& Foley, 2009, p. 1748).

The ANA's (2015b) last two levels of patient advocacy extend beyond the bedside, supporting consumers through seeking positive change in organizations, communities, policies, and legislature. The nurse takes on a social activist role, protecting consumers from inequalities and inconsistencies within the healthcare field through the distribution of quality care and resource opportunities while assessing social changes that should take place to better serve "individuals, communities, and society as a whole" (Bu \& Jezewski, 2006, p. 104). On a more macrosocial level, the nurse, as an advocate, translates individual issues into social change (ANA, 2015b; Bu \& Jezewski, 2006; Schwartz, 2002).

An aspect of advocacy, which the ANA's Scope and Standards of Practice (2015b) fails to mention, is listed in provision three of the ANA's Code of Ethics for Nurses (2015a), which emphasizes: "nurses are ethically bound to protect" (Schroeter, 2014, p. 87) the patient's safety. Choi, Cheung, and Pang (2014) conducted a field study focusing on patient advocacy through the endorsement of safe nursing practices, including patient risk reduction and avoidance of unintentional patient harm. Such actions include proactive and vigilant characteristics, necessitating the nurse to guard patients from harm "arising from patients' health conditions, the hospitalization process, ... omissions and/or errors" (Choi, Chung, \& Pang, 2014, p. 1588-1589) while creating a mentally and physically supportive environment to better facilitate "patient well-being and ... . [the] process of recovery" (p. 1588). Lowe (2012), a practicing nurse and editor of the Journal of Obstetric, Gyneco- logic \& Neonatal Nursing, builds on this component of advocacy through a reflection of a personal experience as a patient. Even when a patient is fully aware of the situation and/or knowledgeable in the field, vulnerabilities still exist, requiring the nurse to uphold advocacy through communication and interventions. The nurse "is the patient's primary advocate and provides the big picture view that helps prevent error in health care and the avoidable complications of illness and hospitalization" (Lowe, 2012, p. 327). Through Lowe's (2012) first-hand experience as a patient, she concludes nurses must (1) hold themselves and the other members of the interdisciplinary team accountable for their quality of care, and (2) always seek help to find answers when uncertainty in the knowledge and execution of proper actions arises. When nurses provide high quality competent care, positive patient outcomes follow.

How nursing actions are carried out should not be dismissed as trivial in reference to patient advocacy. Bu and Jezewski (2006) explore and combine four major patient advocacy theories, finding that each fail to "point out nurses' patient advocacy behaviors are context-based" (p. 103). Context-based individualization creates a patient-centered environment; different situations require modified interventions for supplying patient advocacy (Bu \& Jezewski, 2006).

While the ANA did define "advocacy" in their 2015 edition of the Scope and Standards of Practice, the conceptualization is vague and fails to incorporate the perspectives of the consumer. Because the nurse is central to patient outcome determination, nurses' view of patient advocacy is an important aspect in the execution of patient care. Therefore, this study aims to explore perceptions of advocacy from the consumers' point of view to enhance personal professional nursing practice.

\section{Method Participants}

Participants were recruited via email (Appendix C) and/or flyers (Appendix B) sent through the university's email server. Those who were interested in participating were asked to contact the primary investigator due to limited available seating. Healthcare professionals or individuals with a healthcare background, including nursing faculty and nursing students, regardless of gender, ethnicity, race, or age, were excluded from this study due to the study's aim of representing only consumer 
perspectives of patient advocacy. The selection process for participants was approved by the associated university's institution review board.

A convenience sample of eight students from a southeastern university participated in the study with a response rate of $80 \%$. Gender, ethnicity, age, and area of discipline were the areas of demographic characteristics collected. Of the eight total participants, $50 \%$ were male and $50 \%$ were female. The ethnicity of the sample was $75 \%$ White, $25 \%$ Black. The age of the participants ranged from 18 to $22(M=19.75, \mathrm{SD}=1.67)$. Participants' areas of discipline included the following: athletic training, biology, business, education, forensic science, music, and mathematics. Participants were also asked if they had ever been hospitalized; $75 \%$ reported "yes" while the remaining $25 \%$ reported "no."

\section{Research Design and Procedure}

This phenomenological study was designed to explore the essence and meaning of the concept of patient advocacy from the point of view of the healthcare consumer. Approval of the study design was granted from the university affiliated academic institutional review board. A convenience sample of college students from a southeastern university was recruited through email via the university's email server and flyers posted around the university's campus. Refreshments were provided to the study's participants as an incentive.

Participants were informed that taking part in data collection through focus groups was optional; and an informed consent form, noting the session would be audio recorded, was given to each participant and signed before the onset of data collection. Demographic data was collected as indicated above; no names or other identifying information was collected from the participants.

Qualitative data was collected by the principle investigator through open-ended questions guided by a focus group guide (Appendix E) in which questions referenced the consumers' perspective of advocacy in the healthcare field. A debriefing session was held at the end of each focus group session (Appendix F). Focus groups were audio recorded and later transcribed for analysis of themes.

\section{Findings}

Upon completion of focus group meetings, audio recordings were transcribed into an electronic format for qualitative review. A content analysis was initiated using the selective approach, highlighting the statements that seemed most essential to understanding the consumer's perception of the concept of patient advocacy. Responses were reviewed and then coded by the primary investigator according to their predominant theme. Conceptual files were then created and categorized by thematic distinctions which emerged from qualitative coding.

Data saturation was reached, and the five significant themes identified in the content analysis of focus groups regarding the conceptualization of patient advocacy include the following: personality characteristics; autonomy and self-determination; the patient's values, beliefs, rights, and desires; information disclosure; and patient safety. Participants are cited, and a full transcription of the focus group sessions can be found in Appendixes $G$ and $\mathrm{H}$. Findings were verified by the principle investigator's faculty mentor.

The table below outlines the demographic characteristics of the participants.

\begin{tabular}{|l|l|l|l|}
\hline & Gender & Age & Discipline \\
\hline Participant 1 & Female & 22 & Biology \\
\hline Participant 2 & Female & 21 & $\begin{array}{l}\text { Mathematics } \\
\text { Education }\end{array}$ \\
\hline Participant 3 & Male & 19 & Physical Education \\
\hline Participant 4 & Male & 22 & Music Business \\
\hline Participant 5 & Male & 19 & $\begin{array}{l}\text { Mathematics } \\
\text { Education }\end{array}$ \\
\hline Participant 6 & Male & 19 & Business \\
\hline Participant 7 & Female & 18 & $\begin{array}{l}\text { Applied Forensic } \\
\text { Science }\end{array}$ \\
\hline Participant 8 & Female & 18 & Athletic Training \\
\hline
\end{tabular}

\section{Vague Conceptualizations}

Participants were first questioned on their conceptualization of the general concept of advocacy without the concept being put into any particular context. "Help- 
ing," "supporting," or "backing someone up" were commonly stated interpretations (participant 1; participant 6; participant 8). According to one participant, when you advocate for someone else, it is "almost like a sacrifice, you stick your neck out for someone else" (participant 2).

In reference to advocacy in the context of the healthcare profession, the concept was described as "keeping the patient in mind and their best interest in everything" the healthcare professional does (participant 2). Participants also emphasized the importance of healthcare professionals understanding that physical ailments have an influence on an individual's emotions (participant 4); "you're treating people ... we have emotions ... I am more than a problem that needs fixing" (participant 2). Participants expressed a desire to be treated "more than just a number, [but rather,] like a real person" (participant 2; participant 4). "There is a difference between repairing an object and repairing a person" (participant 4).

\section{Personality Characteristics}

Within the conceptualization of advocacy, many personality characteristics were noted and include the following: "friendly," "personable," "compassionate," "caring," "genuine," "selfless," and "trusting." Each of these characteristics builds on each other, and participants believe that all characteristics are essential in carrying out advocacy.

When the healthcare professional is friendly, the healthcare environment becomes "a more warm and friendly environment" (participant 2) which can decrease the anxiety of patients. According to the Merriam-Webster dictionary (2015), "friendly" can be translated to mean "kind and helpful"; "showing kindly interest and goodwill"; being "cheerful and comforting." The characteristic of being personable arises from that of friendliness; a personable individual is "pleasant or amiable," "easy to get along with," and is "friendly or pleasant in manner" (personable, 2015). Participants suggested healthcare professionals open "up their personal [lives] to their patients" (participant 4) to accentuate personableness and further enhance the realm of patient advocacy.

Through the personality characteristic of compassion, participants believed it essential for healthcare professionals to "ensure the patient is fully cared for" (participant 4), for example, by "staying past [their des- ignated work] hours" (participant 4). When a healthcare professional ensures "sympathetic consciousness of others' distress together with a desire to alleviate it" (compassionate, 2015), healthcare consumers feel as if they are being treated "like a person" (participant 2), or treated justly. Participants expressed a desire to be cared for by someone "who will treat [them] like a person" (participant 2), "not someone who just looks at you like a paycheck, [but someone who] actually [cares about] what they are doing" (participant 4). Genuinely caring for the patient includes actions by a healthcare professional that ensure things "are done to keep [the patient] in good condition" (caring, 2015). In addition, being genuine was a characteristic mentioned by participants, one which encompasses that of sincerity and honesty, "free from hypocrisy or pretense" (genuine, 2015).

Selflessness was delineated by participants as "going out of [the] way to do things for the patient ... [for example,] making them feel more comfortable or explaining the diagnosis" (participant 1). When the patient is shown selflessness, or "great concern" and "generousness" (selflessness, 2015), the value the healthcare professional places upon the patient is made evident. In addition, participants believe "building up trust" (participant 8) is an action encompassed in the concept of patient advocacy. Within a trusting relationship, the patient places "assured reliance on the character, ability, strength, or truth" (trust, 2015) of the healthcare professional; "confidence is placed" (trust, 2015) in the healthcare professional and effective patient advocacy is established.

\section{Autonomy and Self-Determination}

Allowing the patient to fully decide their healthcare course of action was accentuated as a component of patient advocacy: "it's their body, it's what they want to do with it . . you can't really force them to do anything else" (participant 5). Giving the patient the "freedom to make [their] own choices . . . without external compulsion" (self-determination, 2015) and then following through on "what the patient wants" (participant 5; participant 7) was mentioned throughout focus groups as a key element of patient advocacy. Participants admitted that they would prefer healthcare professionals to "give [their] opinion of what [they] think would be best for them" (participant 7) while also giving them alternate options, but in the end, allowing the patient to "pick and 
decide what they should do" (participant 7). The nurse is also seen as a mediator, implementing advocacy through "the communication between the nurse and the doctor to the patient about understanding specifically what the patient wants" (participant 7). "You have to respect what the patient wants, but you also have to save people's lives at the same time" (participant 5).

\section{The Patient's Values, Beliefs, Rights, and Desires}

As an aspect of patient advocacy, participants believe healthcare professionals should be aware of "more than just [the patient's] medical needs" (participant 2), integrating their values, beliefs, rights, and desires into practice and "fighting for that [they] want" (participant 6). A healthcare professional intervention suggestion includes one-on-one time with the patient to further understand their wishes and desires, "to understand exactly what they need" (participant 7). Additionally, "the nurse [or other healthcare professional] may have to step in and give the doctor insight on what the patient is going through" (participant 5) and "push for" (participant 7) their values, beliefs, rights, and desires.

Health professional assertiveness, placing priority on the client's values, is "important because it is good for the wellbeing of the [patient]" (participant 6). During the birth process of one of the participant's family members, some nurses and other healthcare professionals made decisions that were against the desired birth-plan, doing what they, the healthcare professionals, "thought was best" (participant 2). Alternatively, healthcare professionals are to "keep [the] patient in mind" (participant 2); if the patient does not value, believe, or desire a certain intervention or treatment, even if it may be a better decision health-wise, it is priority to remember to "respect what the patient wants" (participant 5) and help them carry out their desires. Advocating for healthcare consumers includes "genuinely caring for and having a patient's back no matter what" (participant 8); patients need healthcare professionals to "make sure their voice is heard" (participant 8).

\section{Information Disclosure}

Informed communication and information disclosure is portrayed by one participant in the following statement: "just tell it to me straight" (participant 2). This individual expressed that being told "every bit of information" can make the patient feel like a priority.
The participants advised healthcare professionals to "put [the patient] in [the healthcare professional's] shoes" (participant 4), helping them think of every possibility and giving potential outcomes of what may arise if they authorize certain decisions.

Based on the assessment data gathered, in one participant's experience, the participant's physician formed a treatment plan while asking for expert advice from other practicing physicians and "trainers" (participant 6). The participant told of how the doctor gave him two general options as a form of treatment; he could either continue to play sports and possibly make his injury worse, or he could stop playing sports to allow his injury to heal. This individual's physician did not give him advice or opinions on what path of treatment to take, but rather used informed communication to lay out the pros and cons of each decision, ultimately allowing the individual to make a fully informed and autonomous decision.

According to group participants, advocating includes "giving [the patient] all the information they need . . . to make their own decisions and [as a healthcare professional,] to not really weigh in on the decision too much" (participant 2). Giving the patient "information on how they are doing" (participant 8) as well as "next step things" (participant 2), or anticipatory guidance, is included in this concept of informed communication, further impressing upon the patient that they are a priority.

\section{Patient Safety}

While participants presented very little opinion on the defining concept of patient safety in reference to patient advocacy, it was a theme within the responses. Participants believe that a proper advocate is one who demonstrates a caring and genuine personality, one "who will make the patient feel as if they are home" (participant 4). When a patient feels like "someone is looking out for [them], [they] feel safe" (participant 3), and when they feel safe, hospitalization becomes a better experience. No patient will be confident in their healthcare professionals' ability to advocate for them if the healthcare professional is unable to safely care for the patient.

\section{Discussion}

Because the majority of previous research defines the concept of patient advocacy from a professional standpoint, the purpose of this qualitative study was to 
explore consumer perceptions with the goal of defining the concept more completely. Many of the themes identified in the current study correlate with findings from previous studies; however, there are a few key differences noted in the discussion below.

One aspect of patient advocacy found in the current study which was absent in previous research findings is that of healthcare professionals' personality characteristics. While previous research mentioned proactive and vigilant characteristics in relation to guarding patient safety (Chio, Chung, \& Pang, 2014), consumers reported that "good character" (participant 4) is a means by which the healthcare professional can best advocate for the patient. When asked what specific actions could be implemented to advocate for the patient, participants listed multiple personality characteristics, including the following: "friendliness," "personableness," "compassion," "caring," "genuineness," "selflessness," "trusting."

Although participants focused more on empowering autonomy though information disclosure and promoting autonomy through the upholding of patients' values, rights, beliefs, and desires, the ability of the patient to make an informed and un-coerced decision was still a reported aspect of advocacy. Previous research draws on two interventions in the preservation of patient autonomy: (1) fully informative communication within the nurse-patient relationship, and (2) the promotion of the patient's values, beliefs, and desires through support of the patient's personal decision. Two of the prominent themes found in the current study reflect these ideas from previous findings and include informed communication in the form of "giving the patient all the information they need for them to make their own decisions" (participant 2), followed by upholding the patient's desires by "[pushing] for" (participant 7) these decisions. The idea of paternalism, the overriding of a "patient's preferences, decisions, or actions" (Zomorodi \& Foley, 2009 , p. 1747) was discussed during focus groups, and participants concluded it is a priority for healthcare professionals to respect and help carry out the desires and decisions of the patient; autonomy must not be ignored.

Empowerment through supplication of emotional, informational, and social support is documented as an important part of the interpersonal nurse-patient relationship aspect of patient advocacy. Findings from the current study accentuate the importance of supporting and defending the patient's desires and autonomous de- cisions. Being thoroughly knowledgeable about the patient's situation, background, thoughts, and desires can be accomplished through one-on-one time with the patient with the goal of further understanding the patient's wishes. Articulating the importance of emotional support, participants expressed multiple times that advocating for a patient includes taking into account that they are an emotional being. Additionally, social support was delineated as an important part of advocacy, supporting patient decisions and being there to listen to the patient when there are questions and concerns. Patient empowerment is the result when informational, emotional, and social support come together through (1) the provision of complete and unbiased information disclosure, and (2) the promotion of patient autonomy via the preservation of the patient's personal values, beliefs, and desires.

A macrosocial level of patient advocacy discussed throughout published guidelines (ANA, 2015b) and previous research established the nurse's function of translating individual issues into social change; however, this aspect of advocacy was lacking in the current study's data. One participant spoke about the need for healthcare professionals to assure the patient's voice is heard; this could be translated into individual advocacy through promotion of the individual patient's desires, or societal advocacy through the nursing role of social activism.

Advocacy is not reserved or given to only certain patients; current research findings build on the idea that every patient needs an advocate. Previous research reported that even when a patient is aware of his or her medical situation and is knowledgeable in the healthcare field, vulnerabilities to errors and incomplete care still exist. The nurse is viewed as the patient's primary advocate, the link between physician and patient who is able to prevent errors and implement holistic and competent patient care.

Participants presented an element of patient advocacy not mentioned in previous research. It is not solely the responsibility of the healthcare professional to advocate for the patient; assuming autonomy is maintained, the patient has a responsibility to fully comply with the decided mode of treatment. The statement "No one can advocate for you if you don't advocate for yourself" implies patient advocacy is a process within a nurse-patient relationship involving a give-and-take connection. 


\section{Importance of Findings}

Previous research findings on the conceptualization of patient advocacy have been supported through the current study. Patient advocacy continues to be a fluctuating concept; however, with a more thorough understanding of not only healthcare professionals' views but also the perceptions of consumers, the actions which conceptualize this important part of patient care can be more efficiently implemented into personal practice. With the consumer's view incorporated into nurses' personal understanding and subsequent actions, individualized patient-centered nursing care becomes proficient.

\section{Limitations and Ramifications}

It is important to recognize that the detailed perspectives of patient advocacy change from person to person and situation to situation. Perspectives can differ according to a consumer's experience with the healthcare system; for example, an individual who has never been acutely hospitalized may not understand the importance of patient advocacy in comparison with someone who has experienced the physical and psychological challenges of an acute hospitalization. Therefore, the conclusions of this study are limited by the continuous evolution of the human perspective based on personal situations and experiences.

The convenience sampling used within this study may not be representative of the entire population and is, consequentially, a source of potential bias. In addition, the participants originate from a southeastern university geographically located in an area with a high level of health disparities. While not all participants geographically originate from this area, this may have affected their answers. In contract, the diverse areas of discipline sustained by participants allows for a broader generalizability of the study.

\section{Future Studies}

Since this study involved only students from the ages of 18 to 22, future confirmatory studies should be carried out with other populations, such as university faculty members, and an increase in age group diversity. Additionally, a more informational perspective could possibly be gained from participants who have had experience with hospitalizations in the past.
Research on the perspectives of patient advocacy should be continued in order to gain a more comprehensive understanding of this developing and dynamic concept.

\section{References}

American Nurses Association. (2015a). Guide to the code of ethics for nurses. Silver Spring, MD: ANA.

American Nurses Association. (2015b). Nursing: Scope and standards of practice. Silver Spring, MD: ANA.

American Nurses Association. (2015c). Nursing's social policy statement: The essence of the profession. Silver Spring, MD: ANA.

Autonomy. 2015. In Merriam-Webster.com. Retrieved from http://www.merriam-webster.com/dictionary/autonomy

Bishop, A. H., \& Scudder, J. R. (2003). Gadow's contribution to our philosophical interpretation of nursing. Nursing Philosophy, 4(2), 104-110. doi: 10.1046/j.1466769X.2003.00125.X

Bu, X., \& Jezewski, M. A. (2007). Developing a mid-range theory of patient advocacy through concept analysis. Journal of Advanced Nursing, 57(1), 101-110. doi: 10.1111/j.1365-2648.2006.04096.x

Caring. 2015. In Merriam-Webster.com. Retrieved from http:// www.merriam-webster.com/dictionary/caring

Choi, S. P., Cheung, K., \& Pang, S. M. (2014). A field study of the role of nurses in advocating for safe practice in hospitals. Journal of Advanced Nursing, 70(7), 1584-1593. doi: $10.1111 /$ jan. 12316

Compassionate. 2015. In Merriam-Webster.com. Retrieved from http://www.merriam-webster.com/dictionary/compassionate

Curtin, L. L. (1979). The nurse as advocate: a philosophical foundation for nursing. Advances in Nursing Science, 1(3), 1-10. Retrieved from http://journals.lww.com/advancesinnursingscience/Pages/default.aspx

Fowler, M. D. (1989) Ethical decision making in clinical practice. Nursing Clinics of North America, 24(4), 955-965. Retrieved from http://www.nursing.theclinics.com/

Friendly. 2015. In Merriam-Webster.com. Retrieved from http://www.merriam-webster.com/dictionary/friendly

Gadow, S. (1989). Clinical subjectivity: advocacy with silent patients. Nursing Clinics of North America, 24(2), 535541. Retrieved from http://www.nursing.theclinics.com/

Genuine. 2015. In Merriam-Webster.com. Retrieved from http://www.merriam-webster.com/dictionary/genuine 
Hewitt, J. (2002). A critical review of the arguments debating the role of the nurse advocate. Journal of $A d-$ vances Nursing, 37(5), 439-445. doi: 10.1046/j.13652648.2002.02110.x

Kohnke, M. F. (1982). Advocacy: what is it? Nursing and Health Care, 3(6), 314-318.

Lowe, N. K. (2012). Reflections on the importance of the nurse. Journal of Obstetric, Gynecologic \& Neonatal Nursing, 41(3), 325-327. doi: 10.1111/j.1552-6909.2012.01365.x

Personable. 2015. In Merriam-Webster.com. Retrieved from http://www.merriam-webster.com/dictionary/personable

Schroeter, K. (2014). Do you use your professional code of ethics? Journal of Trauma Nursing, 21(3), 87-88. doi: 10.1097/JTN.0000000000000049

Schwartz, L. (2002). Is there an advocate in the house? The role of health care professionals in patient advocacy. Journal of Medical Ethics, 28(1), 37-40. doi: 10.1136/ jme.28.1.37

Self-determination. 2015. In Merriam-Webster.com. Retrieved from http://www.merriam-webster.com/dictionary/self-determination

Selflessness. 2015. In Merriam-Webster.com. Retrieved from http://www.merriam-webster.com/dictionary/selflessness

Trust. 2015. In Merriam-Webster.com. Retrieved from http:// www.merriam-webster.com/dictionary/trust

Vaartio, H., \& Leino-Kilpi, H. (2005). Nursing advocacy - a review of the empirical research 1990-2003. International Journal of Nursing Studies, 42(6), 705-714. http://dx. doi.org/10.1016/j.ijnurstu.2004.10.005

Vaartio, H., Leino-Kilpi, H., Suominen, T., \& Puukka, P. (2008). The content of advocacy in procedural pain care - patients' and nurses' perspectives. Journal of Advanced Nursing, 64(5), 504-513. http://dx.doi.org/10.1111/ j.1365-2648.2008.04817.x

Zomorodi, M., \& Foley, B. J. (2009). The nature of advocacy vs. paternalism in nursing: clarifying the 'thin line'. Journal of Advanced Nursing, 65(8), 1746-1752. doi: 10.1111/j.1365-2648.2009.05023.x 


\section{Appendix A}

One University Drive P.O. Box 1510

Pembroke, NC 28372

Institutional Review

Board

FWA 00005281

September 1, 2016

Elizabeth Crawford

Maynor's Honor College

UNCP

IRB Protocol \#: 16-08-003

Dear Ms. Crawford,

The IRB has completed an expedited review of your protocol titled: Examining the Consumer's Perspective of Patient Advocacy" and granted approval.

Please note that if significant changes are made to the protocol, you must submit these changes to the IRB prior to their implementation in your study, as they may change the status of your review. Also, if any unanticipated or adverse events occur during this research, please notify me immediately.

Please include your protocol number (16-08-003) on your final consent forms and in future correspondence regarding this protocol.

Sincerely,

(consider attachment to email as my e-signature)

Roger

Roger Guy, Ph.D.

Professor of Sociology and Criminal Justice

Chair, UNCP Institutional Review Board 


\section{Appendix B}
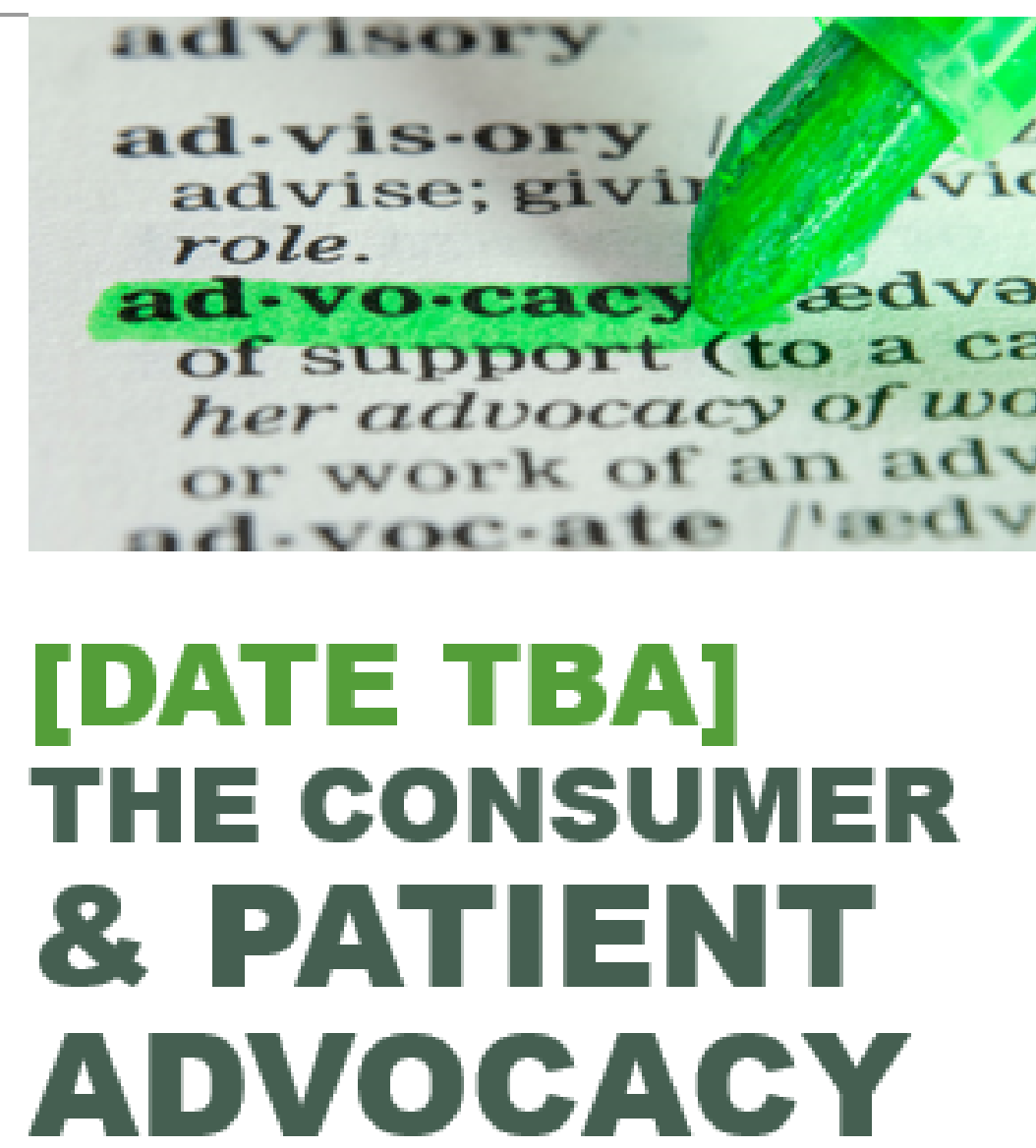

\section{WHAT IS ADVOCACY?}

WHAT IS ADVOCACY NOT?

WHAT FACTORS DETERMINE PATIENT ADVOCACY?

IS PATIENT ADVOCACY IMPORTANT?

Patient advocacy has become a popular topic of discussion within the medical field, however, research lacks information on the consumer's perspective. In order to gain a more thorough understanding of patient advocacy, I need you!

Please come take part in a focus group, lasting approximately 45-6o minutes long so I can explore your perspective of patient advocacy!

IF YOU ARE INTERESTED, PLEASE EMAIL EC0016@BRAVEMAIL.UNCP.EDU
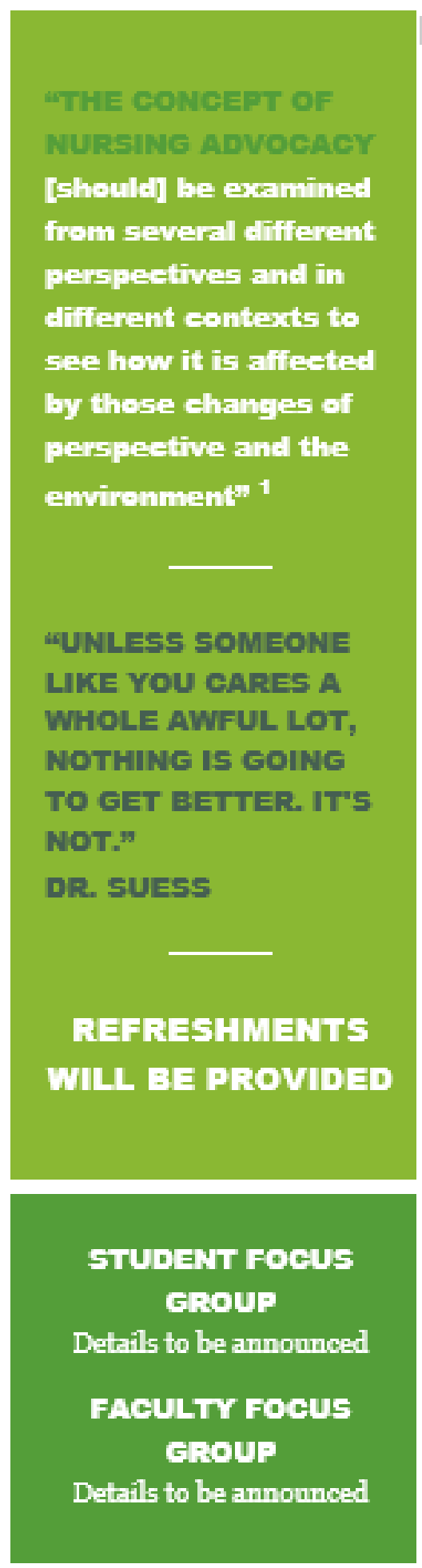

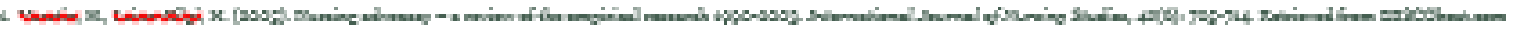

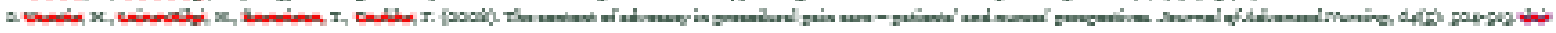

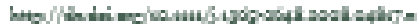




\section{Appendix C}

\section{$\underline{\text { Email Cover for Focus Group Participant Recruitment }}$}

\section{Greetings!}

My name is Elizabeth Crawford and I am a senior undergraduate nursing student at the University of North Carolina at Pembroke. I am emailing in regards to a research study I am conducting for my honors senior thesis project in which I desire to explore the consumer's view of patient advocacy.

I have chosen this specific topic because the literature is lacking in respect to the consumer's viewpoint on the concept. I believe that in order for healthcare professionals to better serve their patients, a more complete understanding of patient advocacy must be constructed, one which takes into account the consumer's mindset. To understand the consumer's perspective, I will be conducting two separate focus groups, one consisting of students and the other consisting of faculty.

Participation involves taking part in a small five to seven participant focus group discussion which will last approximately (45-90) minutes. Answers to open-ended, opinion-based questions will be asked during the focus group meeting, which will be audio recorded and later transcribed and analyzed.

The focus group discussion will remain anonymous; I will ask the participants to share general demographic information, however this data will not be recorded or attached to the individual participants. No identifying information will be recorded. There are no risks involved in taking part in a focus group; however, answering questions is completely voluntary. You may refuse to take part in this study or, if you decide to participate in the study, you may decide not to answer any questions that make you feel uncomfortable or to stop the interview at any time.

I have attached a flyer which gives a brief informational overview of the purpose of my research. Because seating is limited, I am asking that both students and faculty pre-register to volunteer. Those who are interested in participating should email me at ec0016@bravemail.uncp.edu; I will contact them with further information.

I so greatly appreciate your help in aiding my recruitment of focus group participants! Thank you for considering taking part in my project.

Many thanks for your consideration in this matter!

Elizabeth Crawford 


\section{Appendix D \\ Consent Form \\ University of North Carolina-Pembroke \\ Consent to Participate in a Research Study \\ Adult Participants \\ Social Behavioral Form}

IRB Study \# 16-08-003

Consent Form Version Date: September 2016

Title of Study: Examining the Consumer's Perspective of Patient Advocacy

Principal I nvestigator: Elizabeth Crawford

UNC-Pembroke Department: Maynors Honors College

UNC-Pembroke Phone number: (910) 521-6841

Faculty Advisor: Dr. Jennifer Johnson

Study Contact telephone number: (910) 987-7356

Study Contact email: ec0016@bravemail.uncp.edu

\section{What are some general things you should know about research studies?}

You are being asked to take part in a research study. To join the study is voluntary. You may refuse to join, or you may withdraw your consent to be in the study, for any reason, without penalty.

Research studies are designed to obtain new knowledge. This new information may help people in the future. You may not receive any direct benefit from being in the research study. There also may be risks to being in research studies.

Details about this study are discussed below. It is important that you understand this information so that you can make an informed choice about being in this research study. You will be given a copy of this consent form. You should ask the researchers named above, or staff members who may assist them, any questions you have about this study at any time.

\section{What is the purpose of this study?}

The purpose of this research study is to learn about the consumer's perspective of the concept of patient advocacy.

You are being asked to be in the study because current research explores the topic in reference to healthcare professional's perspective, but fails to examine how the consumer views the concept.

\section{Are there any reasons you should not be in this study?}

You should not be in this study if you have been/are currently employed in the healthcare profession.

\section{How many people will take part in this study?}

If you decide to be in this study, you will be one of approximately twenty people in this research study.

\section{How long will your part in this study last?}

You will be actively involved in this study for the length of the focus group meeting which will last approximately 45 to 90 minutes.

\section{What will happen if you take part in the study?}


You will be asked open ended questions about the concept of advocacy in the healthcare setting in a group consisting of five to six other individuals. Meetings will be audio recorded and later analyzed.

\section{What are the possible benefits from being in this study?}

Research is designed to benefit society by gaining new knowledge. You may not benefit personally from being in this research study.

\section{What are the possible risks or discomforts involved from being in this study?}

The breach of confidentiality risk will be minimized by anonymizing the study.

Risks of this study are considered minimal and are expected to be no greater than those normally encountered during daily life.

\section{How will your privacy be protected?}

Names will not be recorded, demographic data will be taken as a qualifier of data comparisons. Records will be password protected and remain anonymous.

Participants will not be identified in any report or publication about this study. Although every effort will be made to keep research records private, there may be times when federal or state law requires the disclosure of such records, including personal information. This is very unlikely, but if disclosure is ever required, UNC-Pembroke will take steps allowable by law to protect the privacy of personal information. In some cases, your information in this research study could be reviewed by representatives of the University, research sponsors, or government agencies for purposes such as quality control or safety.

Group meetings will be audio recorded and later transcribed and analyzed for consumers' perspective of patient advocacy data points. Audio recordings will be stored until the completion of the research study and transcriptions will be included in the final study write up.

Check the line that best matches your choice: OK to record me during the study Not OK to record me during the study

You are not required to reveal your name, and may use a fictitious name. Focus group discussions are to remain anonymous, requiring each participant to refrain from revealing anything learned from discussions.

\section{Will you receive anything for being in this study?}

You will not receive anything for taking part in this study.

\section{Will it cost you anything to be in this study?}

There is no cost to you except for your time taking part in a focus group.

\section{What if you have questions about this study?}

You have the right to ask, and have answered, any questions you may have about this research. If you have questions, or concerns, you should contact the researchers listed on the first page of this form.

\section{What if you have questions about your rights as a research participant?}

All research on human volunteers is reviewed by a committee that works to protect your rights and welfare. If you have questions or concerns about your rights as a research subject you may contact, anonymously if you wish, the Institutional Review Board at 910.775.4359 or by email to irb@uncp.edu. 
Title of Study: Examining the Consumer's Perspective of Patient Advocacy

Principal I nvestigator: Elizabeth Crawford

\section{Participant's Agreement:}

I have read the information provided above. I have asked all the questions I have at this time. I voluntarily agree to participate in this research study.

Signature of Research Participant

Printed Name of Research Participant

Signature of Person Obtaining Consent

Printed Name of Person Obtaining Consent
Date

\section{Date}




\section{Demographic Data}

1. What is your gender?

-- Male

--- Female

2. What is your ethnicity?

White

Hispanic or Latino

- Black or African American

-- Native American or American Indian

--- Asian / Pacific Islander

Other:

3. What is your age?

4. What is your area of discipline?

5. Have you ever been hospitalized? $\quad \mathrm{Y}$ or $\mathrm{N}$ 


\section{Appendix E \\ Focus Group Questionnaire Guide}

1. What is your definition of advocacy? (in general)

Ask for examples of advocacy:

When have you seen someone advocate for another?

When have you advocated for another?

Theoretical example of advocacy.

2. Is advocacy important in healthcare?

Follow up questions: Why do you believe advocacy in healthcare is important?

Why do you believe advocacy in healthcare is not important?

3. What do you believe is encompassed in the concept of patient advocacy?

Follow up questions: What factors determine patient advocacy?

How can a health care professional advocate best for their

patient?

What are specific actions that constitute patient advocacy?

4. Are there any individuals who require extra vigilant patient advocacy?

Follow up question: Are there any individuals who you believe do not require patient advocacy?

5. How does the nurse, or other health care professional, encourage patient autonomy?

6. Are there any improvements within patient advocacy that can be made to ensure higher quality care within the health care field?

7. Before we leave today, I would like to re-ask you a question similar to the ones I asked at the beginning of our session: What is your definition of consumer advocacy in relation to the health care field? 


\section{Appendix F \\ Debriefing Manuscript}

Because current research explores the topic of patient advocacy related to the healthcare professional's perspective and fails to examine those of the consumer, I have asked you to partake in a study group discussing the topic. The goals of this study is to create a comprehensive interpretation of patient advocacy using the data collected today from this focus group. Your perspective has been audio recorded and will later be transcribed then analyzed for themes. Your perspectives will support a gain in understandingof perceptions of patient advocacy from the consumers' point of view, in turn, allowing the enhancement of personal professional nursing practice.

Questions during the focus group included the following topics: your definition of advocacy; your belief in the importance of patient advocacy; and your belief in the components of patient advocacy.

Do you believe that the questions asked during the study were appropriate and sufficient enough for the purpose and goals of this study?

How do you believe this study could be improved?

What were your perceptions before, during, and after the study's focus group meeting? Study results will be disseminated via The Maynor's Honors College Fall 2016 Symposium at the end of this current semester. If you are interested in viewing the end result of your participation, please feel free to email me!

Your participation is much appreciated. Thank you for sharing your time and personal views on patient advocacy. 


\section{Appendix G \\ Focus Group 1 Transcription}

Moderator: What do you believe advocacy to be in general? So what is your definition of advocacy?

Participant 1: I would say, helping or supporting someone with something.

Participant 2: Almost like a sacrifice, when you advocate for someone else, you stick your neck out for someone else, sacrifice your time for someone else.

Moderator: Does anyone have a specific example? Or is there an example of when you advocated for someone, just in general.

Participant 1: I guess going out of your way to help someone with their homework or something when you are busy

Participant 3: Okay, I was just trying to figure out what advocacy is.

Participant 4: Same.

Moderator: So how, in your terms, just in everyday life would you advocate for someone?

Participant 3: Let's say, I'm in the computer lab and someone forgot their paper, I give them

some paper. I bought the paper, I'm losing money, quote un-quote, I guess.

Moderator: There is no right or wrong answer, it's your own opinion.

Participant 4: I guess letting a customer skip you in line, I guess, if they had less items than you.

Moderator: Do you believe advocacy is important in healthcare?

Participant 4: In the same manner of the definition that we just used?

Moderator: Just in general.

Participant 4: Like advocacy in the same definition that we used?

Moderator: Maybe I should ask first what you believe advocacy would be in the healthcare field. Participant 3: Is it like, in the ER, when you've been waiting but someone else comes in and they are worse off and they're like, okay, we take you now instead of so-and-so even though they've been waiting?

Moderator: Or, how would someone who is working in the healthcare field, say a doctor or a nurse or even someone who cleans up someone's trash in the hospital, how could they advocate for a patient?

Participant 2: I guess just trying to keep the patient in mind 24/7. Like in my field, in the educational department, you really want to have the student's best interest in mind with everything you do, and so I guess for everybody in the healthcare field, advocacy is just keeping the patient in mind, and their best interest 24/7 in everything they do.

Moderator: Anything else? [Pause] Put yourself in the situation, if you haven't been in the hospital before, it can be kind of hard. If you were a patient in the hospital, how would you want someone to advocate for you? Or how would you define, say a nurse or a physician, how would they advocate for you?

Participant 2: Well you are more than just a problem that needs fixing. Like if I go in with a broken bone, I'm more than just a broken bone that needs fixing; I am a person with feelings and emotions and family that are worried about me and I guess just treating me like more than just a number, like a real person.

Participant 4: Yeah, it's not like you are just taking your computer into a computer shop, or something; you are dealing with a human that has emotions. There is a difference between repairing a person versus repairing an item.

Participant 1: I agree with them. 
Moderator: what kind of specific actions can someone do to advocate for a patient? Like what kind of things would they want to encourage, or what kind of things would they want to make sure they do for the patient?

Participant 2: Just be more personable, I guess, more friendly. Just being aware of their needs and their family's needs, more than just their medical needs.

Participant 3: Like going and getting that extra pillow, if they want another pillow, or some more blankets, or something like that. Even though if it's not protocol or whatever.

Moderator: So with that said, do you guys believe that advocacy is important in the healthcare field?

Participant 1: Yes.

Participant 3: Oh yeah, definitely, especially if you are in there you are going to want that; you are going to want someone looking out for you. So, if you feel like someone is looking out for you, you feel safe. It is a better experience for you, not saying that the hospital is a good experience, but it would be a better experience.

Moderator: Anyone else want to go into more detail why you believe advocacy is important in the healthcare field?

Participant 2: Well me personally, I don't like hospitals. Like even doctor's offices freak me out on some level. And so just being, like, friendly or whatever, and just make it a more warm and friendly environment just chills me out; even if I am just going for a check-up, I get really anxious.

Moderator: I may have asked this question already, but what do you believe is encompassed in patient advocacy? What factors determine patient advocacy? [pause] I feel like this is a good question too: how can a healthcare professional advocate best for their patient? [pause] What really helps me figure out what advocacy is is putting myself in the patient's shoes.

Participant 4: Well, I guess start off by evaluating the characteristics of the staff that you hire. Make sure that they have a good character before putting them in your office.

Moderator: For you, what is considered "good character" to be within them in the medical field? Participant 4: Somebody that is very caring, genuine, who will make the patient feel as if they are at home.

Participant 2: Someone who is really compassionate, who will treat you like a person.

Participant 4: Not someone who just looks at you like a paycheck, they actually care about what they are doing.

Moderator: Do you believe there are any individuals who require extra vigilant patient advocacy? So anyone who requires someone to advocate for them more than the regular patient? Participant 1: Older people, maybe, and children.

Participant 4: Not sure if it is appropriate to say this or not, but special needs.

Participant 2: People that require a little more patience, like older people or special needs; and for children it is a little more emotional for the parents. It would be one thing if they themselves were getting surgery, but, like, their three-year-old daughter getting surgery, it's going to be way higher stakes.

Moderator: And are there any patients who do not require patient advocacy?

Participant 4: I think everyone deserves someone who will advocate for them.

Moderator: Anyone want to expand on that?

Participant 4: Well, getting back to what we were saying, you're I am . . . , you are not treating objects.

Participant 2: We have emotions.

Participant 4: I don't think there is an emotion-less person out there. 
Participant 2: Even the people who say, "Oh I am fine," and whatnot and "You don’t need to help me out," they still need an advocate.

Moderator: How does the nurse or other healthcare professional encourage patient autonomy? And autonomy is the patient being able to make their own decisions with their healthcare. Selfdetermination, they themselves being able to make healthcare decisions.

Participant 2: Well, I think of my older sister, she just had a baby recently, and some of the nurses, not all of them, kind of made snap decisions during the labor process for her that were against her labor plan. She had made a labor-birth plan, like how you would like things to go; and of course it's not always going to go like that, but most nurses knew her enough that they would go by her decisions and her husband's decisions, and some would do just what they thought was best. So, I guess, just don't do that, just have your patient in mind; if your patient doesn't want to do this type of thing, even though that's the best decision health-wise, it might make them uncomfortable or something.

Moderator: Anything else?

Participant 4: I’ve never really seen this first-hand.

Moderator: If someone was advocating for you, whether it be in education, like you going to school, how could someone help you with student autonomy, you making complete decisions academic-wise?

Participant 4: Like an advisor?

Moderator: How could they advocate for you?

Participant 4: Put themselves in your shoes. Helping you think of every aspect that could happen; giving you potential outcomes of what could happen if you made certain decisions.

Moderator: So informed communication?

Participant 4: Yes.

Moderator: Do you guys have any personal experiences with patient advocacy or the lack of? Whether it be at the doctor's office or the dentist, a hospitalization?

Participant 4: Are you asking for specific instances?

Moderator: Yes, happening to you or to other people or whatever you feel like you would be willing to share.

Participant 2: I have thyroid problems, and so my thyroid doctor ... I've been to a lot of doctors growing up because I've had some other problems, that's why I hate doctors. But my thyroid doctor is really awesome. Like she came in and she just told me, she's like, "You have this, and this is what is going to happen and you can either do this or you can do this.” And she just told it to me straight and she didn't beat around the bush and she told me all of the things that might happen and we did some tests and then she put in a prescription and I'm just on some medication, that's it, it's not that serious. But she put in the prescription as soon as possible because it was right before this semester started and I live three hours away, and so she was like, "I am going to get this to you as soon as possible just so you can go ahead and start school and you won’t be dealing with this issue anymore.” I was just like, “This is awesome!”

Moderator: And how does that type of patient advocacy make you feel?

Participant 2: It makes me feel like a priority and that everybody is telling me every bit of information. Like some doctors I feel like they wouldn't tell me every bit of information just because I am younger; I was like 18 at the time or 19 at the time, and I am just like, "Tell it to me straight, like I am an adult. Just tell me what is going to happen.” I felt like they would keep things from me or not tell me the possibility of something might happen. But this doctor told it to me straight and I was like, "Okay, this is awesome.

Moderator: Would you like to add anything that you feel is important to understanding what patient advocacy is? 
Participant 4: Well first, the definition of advocacy.

Moderator: Well, I mean advocacy has a standard definition, but what comprises the specific actions of someone carrying out advocacy can mean a whole world of things. 'Cause, I mean, advocacy is standing up for someone.

Participant 2: Going the extra mile.

Participant 1: Maybe like selflessness.

Moderator: How does someone in the healthcare field show selflessness?

Participant 1: I guess going out of their way to do things for the patient, you know, like, making them feel comfortable or explaining the diagnosis.

Moderator: What other characteristics would you guys say?

Participant 2: Being personable, compassionate.

Moderator: How would a healthcare professional be compassionate towards the patient, or stick up for them? What kind of specific actions would they do?

Participant 4: Staying past hours or past their time for them to go to ensure that customer, or patient, is fully cared for.

Participant 2: Just like telling them all the info, giving them all the information they need for them to make their own decisions and to not really weigh in on the decisions too much.

Participant 4: I guess opening up their personal life to their patients. Maybe personal contact information if they need help beyond the office.

Moderator: The last question I have on here is kind of similar to what we have already been talking about. What is your definition of consumer advocacy in relation to the healthcare field? Like if you could sum it up into one or two sentences.

Participant 3: Just being straight up about the costs and how the insurance will work. Not being like, "Oh, your insurance might cover it." Just like how much is it going to cost and is the insurance going to cover this. This is what you are going to have to pay and this is what you are not going to have to pay. They will know what to expect, as far as financial needs. That comes after everything is done.

Moderator: I know the healthcare professional cannot tell the patient everything without them asking questions, but what kind of things you think, let's say the nurse, should do or say to the patient without the patient having to ask?

Participant 2: Maybe like possible side effects, like next step things. Like you should expect this to happen or this to happen, good and bad. And then what you should do to make yourself better on your own terms, like don't eat this or get more exercise, or something like that. Kind of like next step things, but also before things happen, like prep; like before and after they go through whatever they are going through; what they should do to make sure they are checking all the boxes.

Participant 4: Making sure that the patient goes the extra mile to help the doctors help them. Make sure that they are doing their part and following through.

Moderator: So compliance?

Participant 4: Yeah. Making sure they are going the extra mile to fully comply.

Moderator: So it's not just the healthcare provider, it's also the patient to help encourage patient advocacy?

Participant 4: Yes.

Participant 2: Like in physical therapy, if you don't go home and do the stretches and exercises yourself every day then you are not going to benefit.

Moderator: Like no one can advocate for you if you don't advocate for yourself.

Participant 4: Yes.

Participant 2: Yes. 


\section{Appendix H}

\section{Focus Group 2 Transcription}

Moderator: Where have you seen someone advocate for another person? Or when have you advocated for another person?

Participant 5: Well, I've never advocated for anybody, but my definition is probably, just go with the flow. Like whatever they want to do, you can't really force them to do anything else; it's their body, it's what they want to do with it. If they want to keep going with treatment or if they want to stop, then they can stop, just let them go with the flow.

Participant 7: I would say that patient advocacy is, you should give your opinion of what you think would be best for them, but also give them an alternate option and then have them pick and decide what they should do. More of the route of, I think you should push for what they want. Participant 8: Supporting someone or backing someone up.

Participant 6: So like fight for somebody, I guess?

Moderator: Well, it doesn't have to be an instance for you. If you were to think of someone advocating for someone else, what would you picture?

Participant 6: My doctor advocated for me because he told me I shouldn't go out on the field because if I would have, I wouldn't be able to play any more football because if I got hit in my leg again, I would crack my shin completely through.

Moderator: And how do you think a nurse or a doctor in your situation or in any situation, what actions can they take to accomplish patient advocacy or advocate for their patient?

Participant 6: If there are possible ways, you could try to find all the possible ways to try to find, to let them continue doing what they are doing. Like, say for me, play football, there was no way he could help it; he went and talked to all his trainers, people in the military who got trained for it, and they also said "don't do it," so he did extra to ask all the doctors and trainers that he knew. Moderator: Are there any small things that you think they could do for a patient to make a patient feel like they have been advocated for?

Participant 6: Just that they see you are trying for them, trying to help them out.

Moderator: If you were a patient, how would you want someone to advocate for you? You said you have been in the hospital before; is there a time you felt that one of the nurses or anyone there was there advocating for you?

Participant 5: I mean, when I was in the hospital and broke my left arm, and every other time it was with concussions, so I really had no chance of defending for myself so people had to do stuff for me. So I don't even know when advocating happened in that time frame besides them doing what they needed to do to make me feel better. So I am pretty sure they made decisions based on what my family wanted and on what they saw.

Moderator: If you were in the healthcare field, how do you think you would advocate for somebody else?

Participant 5: To make sure they get the best treatment, I would run it by them first, tell them what's going to happen or tell them what can happen as long as they give me the go-ahead. So I can kind of give my two-cents on what should happen to make them better, and give them support on it, like back up and saying it is safe or that it's been tested multiple times and the results come out strong. And if I know they want to leave, but that's not the best thing to do or the right thing to do, I can always try to get them to stay based upon what they really need Moderator: Do you think [patient advocacy] is important in healthcare? 
Participant 6: Yes, it is important because it is good for the wellbeing of the person that they are talking to or trying to help, like fight for them or something they are doing.

Participant 5: I mean, yeah, it is important. You have to find the best way possible to treat your patients. You can't just let someone who got stabbed or shot walk around on the streets, you got to make sure they get their fluids and their attention. It's to the point that if people didn't have advocacy within the medical field, people would probably be more unhealthy without it.

Participant 8: Yes. I feel like if I were a patient, I would want the nurse to tell me options, but mention what they have seen work best. Give their opinion on it.

Participant 7: I think it is important, because in the long run, you can't get sued if you take care of the patient the way they want to be treated.

Moderator: Are there any other reasons why you think it is important?

Participant 7: Because it is their health and they should have their opinion with what they do with their body.

Moderator: Are there any instances where you think it isn't important for patient advocacy in the healthcare field?

Participant 6: Pulling the plug, I mean like if you have to tell somebody to do that, that's probably the only time, even though that is probably important, like nobody would want to hear that. That's the only time I can think that it wouldn't be good.

Moderator: Okay so like it wouldn't be good for patient advocacy in general at that point because even though that would be what is best for them, no one wants to do that kind of thing?

Participant 6: Yes.

Moderator: What do you believe is encompassed in the term "patient advocacy," so what things do you think dictate patient advocacy and special circumstances or actions that you think would be necessary for patient advocacy?

Participant 5: Probably the same thing; if they are unable to answer, or anything, the doctors have a full go-ahead to do what they feel is necessary, or if they feel they are deemed unsafe, then they have to do what they have to do to get them to a safe level.

Participant 6: The main thing, I think, is help, really. Basically just to help someone more. Moderator: And what factors do you think determine it? So like what things can go on that you think will either require a situation where you will need patient advocacy or where you don't need patient advocacy?

Participant 6: Maybe, for like example, with me and my leg, you would need it then because if he didn't tell me that, I would have went back out there and I would have gotten hit and then I would play no more. You probably always will need it, but, like with the answer before, sometimes people don't want to hear or do the things they are told, like with pulling the plug for someone and their suffering supposedly, but you are not going to want to hear that if they are really close to you.

Participant 7: If you are in a coma, they can talk to your family members on what they think you would want them to do, and then if you are awake, they can ask you, and like if you want water, if you need help getting something or doing something that they can help you with it.

Moderator: Is there anything else that you think they could be doing to advocate for you? Participant 7: They can make sure you get the best doctors and the best care possible.

Participant 8: Building up trust and giving the patient information on how they are doing. Being there to listen to the patient if they have any concerns, questions, etc.

Moderator: And do you think there are any circumstances where a patient requires more advocacy or when you need more patient advocacy at certain times?

Participant 5: I mean, yeah, you have to respect what patients want but you also have to save people's lives at the same time. You have to make sure people are getting the correct attention, 
they just can't treat everyone different. And like I said, if they are unable to answer anything, then you have to step in and let the doctors do what they want because they know what's really best for them at that moment. So yeah, at certain times it is needed more.

Participant 6: Well, in my situation, I didn't need that much because all he had to do was tell me, and once I heard "a broken bone” I was like, "I am not going to play anymore.” But some other people may not need that, they may need extra help, or for you to go fight for them more with their situation.

Moderator: And do you feel that there are any cases where a patient might need more patient advocacy?

Participant 7: If there is a person with a disability that needs more help and care because they do not understand what is going on at the given point, then they need more help than other people. Participant 8: Some nurses may need to advocate more. If the patient doesn't understand something the doctor says, the nurse could help the patient. Patients that can't physically speak or have mental issues may need more advocacy.

Moderator: So how does a nurse encourage patient decisions? What actions do you think the nurse could take to help encourage, like help encourage the doctor to do what they want, because sometimes the doctor might be against it, but often the nurse will push what the patient wants Participant 5: Go from the standpoint not what the doctor thinks is best but what the patient thinks is best, because they may not have the money or anything to keep on going with stuff, so they are going to have to go from the standpoint is it really worth it to keep going when nothing is happening or nothing is changing. So the nurse may just have to step in and give the doctor an insight on what the patient is going through.

Moderator: How do you think a nurse would encourage a patient's decision being made? What steps do you think a nurse could take that would advocate for what the patient wants?

Participant 7: They could talk to each doctor that they think is the right fit for the patient and advocate for what they want and what that patient wants from the doctor, and if the doctor doesn't do what the patient wants, then take it a step further up above the doctors. [pause] So kind of like try to find or feel out the doctors for the patient, to see which doctors are more likely to do what the patient wants. Because that has actually happened to my grandmother. The one doctor was willing to do what she wanted and the other doctor was kind of like, I am not going to work on you unless you do this, kind of thing. And it was like, excuse me? So, like trying to find the doctor for the patient that will do what they want.

Participant 8: By listing out all the options a patient has and ultimately letting the patient decide. Moderator: How do you think the nurses themselves can advocate for a specific patient decision? Like it might not be a decision that everyone in the field agrees with, but how do you think the nurse can still try to advocate, like what actions taken to actually still advocate for the patient, whatever the patient wants, no matter what? [pause] Do you think that would be hard ethically? Participant 6: That would be hard, because if everyone in your field is telling you not to do it because it's like bad or something, but that patient wants it. You could give them an alternate something, something that everyone else would agree with, but that the patient would still like. Moderator: Like let's say in cancer, you don't want to suffer through it but the doctor knows you have a chance of living if you get this treatment, but you just might not want to go through it, you might just want to say I am just going to enjoy life and whatever happens, happens, and not have to go through the pain of chemo. What do you think a doctor or a nurse, how could they react or what actions could they take to make you feel that they are actually advocating for what you want or pushing for what you want?

Participant 6: I watched a movie similar to that and the doctor in it, he told them all the ways that she could go with the cancer, but she didn't want to go through with any of the medications. He 
said okay that is your decision and he went with her decision, but the doctor sill fought for her because he was showing that he was fighting by telling her every way she could go besides just not taking the treatment. Instead of death, she could actually have a good chance at living. Moderator: So he tried to influence her other ways by showing her what kind of life she could have had or what good things could happen if she did this. Instead of saying, you should just do this.

Participant 6: Yes.

Moderator: Within the healthcare field do you think there are any steps that can be taken by anyone to improve patient advocacy and trying to fend for the patient?

Participant 8: If a patient needs extra support, just be there for them.

Participant 5: Probably the nurse has to do more of the dealing with that since they are the ones taking care of them the most, like always checking on them and see how they are doing.

Moderator: So more like focus for nurses to deal with patient advocacy?

Participant 5: Yes. That way they can figure out on both ends what needs to happen and what doesn't need to happen.

Participant 7: Hospitals and services should provide a specific person per patient to help them through the process of advocating for themselves. And they should provide scheduled times with that provider and help them solve the situation.

Moderator: Are there any steps you think the nurse could take to specifically improve the advocacy that nurses do?

Participant 7: They could talk more one-on-one with the patient to understand exactly what they need.

Moderator: So more time with the patient?

Participant 7: Yes.

Participant 6: I think it is pretty good now, just make sure that every nurse and doctor does this. I don't know most people, if they do it or not, but with my doctor, he did it for me. And a different doctor, he had my aunt before she passed away with cancer, he helped her, he was like, "You should do this treatment because it will help your life, it will give you better chances of life for a longer life. And even though she passed away, she still lived longer than she was supposed to. Moderator: And what do you think, or how would you say your definition of patient advocacy is in relation to the healthcare field? So not just advocating for someone in general, but your ideas of how you have patient advocacy when it has to do with someone in the hospital. How would you define patient advocacy itself, like what would you say it is?

Participant 5: It's what the patient wants, basically.

Moderator: So doing what the patient wants?

Participant 5: Yes. If the patient wants something, then the doctor has to respect it, unless it's deemed you definitely cannot have that type thing. It's more of what the patient wants to do and how to go about things.

Participant 6: Just fighting for what someone wants, like their wish, just fighting for that.

Participant 7: It is the communication between the nurse and the doctor to the patient about understanding specifically what the patient wants

Participant 8: Genuinely caring for and having a patient's back no matter what. Make sure their voice is heard. 